\title{
Los retratos de la autora: el caso de Ángela Figuera Aymerich*
}

\section{The Portraits, of the Female Author: the Case of Ángela Figuera Aymerich}

\author{
RAQUEL FERnÁNDEZ MENÉNDEZ \\ Facultad de Filosofía y Letras \\ Universidad de Oviedo \\ C/ Amparo Pedregal s/n. Oviedo, 33011 \\ fmraquel@uniovi.es \\ Orcid ID 0000-0003-3033-5517
}

RECIBIDO: 30 DE ABRIL DE 2019 ACEPTADO: 13 DE JUNIO DE 2019
Resumen: La proliferación en los últimos años de los estudios autoriales, de la mano de especialistas como Nathalie Heinich, Dominique Maingueueau, José-Luis Diaz o Jérôme Meizoz, ha posibilitado un nuevo análisis de la iconografía del escritor que permite comprenderla como uno de los elementos fundamentales que el régimen mediático pone a disposición del autor para garantizar su visibilidad. Sin embargo, a pesar del aumento de trabajos en torno a esta iconografía, aún no se ha avanzado en estudiar las tensiones entre género y autoría a través de los retratos de las escritoras. En este artículo se recurre a este nuevo paradigma crítico y a la teoría literaria feminista para analizar algunas de las fotografías de la poeta Ángela Figuera Aymerich (Bilbao 1902-Madrid 1984) como parte de un proceso de representación como mujer y autora en el campo cultural de los años cincuenta en España. El estudio de tres retratos representativos de su imagen mediática demuestra que el significado de cada imagen no es unívoco, sino que varía según el espacio editorial en el que el elemento fotográfico se localice (la prensa, los libros propios o las antologías poéticas) y de los discursos que rodean al paratexto.

Palabras clave: Literatura española. Estudios culturales. Estudios de género. Autoría. Poesía española de posguerra. Ángela Figuera Aymerich.

\begin{abstract}
The proliferation over the last few years of studies around the question of the author, with the research of specialists such as Nathalie Heinich, Dominique Maingueneau, José-Luis Diaz or Jérôme Meizoz at the forefront, has opened a new perspective for the analysis of the iconographic elements that identify the author in the media regime. That enables us to comprehend these as one of the most important tools that guarantee the visibility of the author in the literary field. However, despite the increasing number of research work, there has not been an advance in the study of the tension between gender and authoriality through the analysis of the portraits of women writers. This article recurs both to this new critical paradigm and to feminist literary theory in order to study some of the photographs of the poet Ángela Figuera Aymerich (Bilbao 1902-Madrid 1984) as part of a process of representation as a woman and an author in the Spain of the fifties. The study of three representative portraits show that the meaning of each image is not univocal but vary from the editorial space in which the photographic element is placed (the press, the books or poetic anthologies) and the discourses that surround the paratext.
\end{abstract}

Keywords: Spanish Literature. Cultural Studies. Gender Studies. Authorship. Spanish Poswar Poetry. Ángela Figuera Aymerich.

* Este artículo se enmarca en el Programa Severo Ochoa (referencia PA-17-PF-BP16126) de Ayudas predoctorales para la investigación y la docencia del Gobierno del Principado de Asturias. 


\section{El RETRATO DE LA AUTORA: DESNATURALIZACIONES DE LA POSE}

L

os retratos del escritor constituyen una de las facetas de la relación entre literatura y fotografía que más atención ha recibido recientemente por parte de la crítica especializada (Ferrari/Nancy; Dewez/Martens; Pérez Fontdevila 2011; Martens/Reverseau; González Treviño). Este creciente interés ha de enmarcarse en el enorme caudal teórico que en los últimos años se ha producido en el análisis del discurso y la sociología de la cultura francófonas en torno a la figura del autor, entendida ahora como parte de un complejo proceso institucional y político que es consustancial al campo literario moderno (Pérez Fondevila/Torras Francés 2015, 2-3). Especialistas como Dominique Maingueneau, José-Luis Diaz o Jérôme Meizoz han articulado con eficacia una respuesta al debate que da comienzo en 1968 con la publicación del célebre artículo "La muerte del autor" de Roland Barthes, donde la escritura se comprendía como un lugar de pérdida de toda identidad (Barthes 65). Este nuevo enfoque permite cuestionar tanto la autonomía del texto proclamada por Barthes como la existencia del autor como sujeto pleno, anterior a la obra (Pérez Fontdevila/Torras Francés 2016, 17-18), y recuperar las ideas de Michel Foucault en torno a una "función autor" (Foucault 38-40), con el fin de dar cuenta de la complejidad de los procedimientos de atribución de un discurso a un determinado individuo.

$\mathrm{Al}$ considerar las múltiples facetas que vertebran la noción de autor, los trabajos citados asumen que la localización del creador en el "régimen mediático" (Heinich 2012) motiva una serie de estrategias destinadas a visibilizarlo y consagrarlo en el espacio social, que se manifiestan tanto en los textos y su periferia como en la proyección pública de sus rasgos físicos, a través de los que el autor se autorrepresenta y contribuye a formar en los demás una determinada imagen de sí mismo. Mediante nociones tales como "escritor imaginario" (Diaz), “imagen de autor" (Maingueneau), "ethos” (Amossy) o "postura" (Meizoz 2015), estas investigaciones coinciden en comprender la autoría como un conjunto de piezas producidas colectivamente por el escritor y los distintos agentes externos que componen el campo literario (críticos, profesores o antólogos, entre otros). De esta manera, estos términos permiten asumir una nueva óptica para abordar los espacios paratextuales (prefacios, prólogos, manifiestos o diarios) y los instrumentos que, como la fotografía, sirven para situar al creador en el régimen mediático, y, así, es posible analizar la iconografía (ya sea en forma de fotografías, ilustraciones o esculturas) como un ele- 
mento que toma parte en la construcción del sentido del texto y contribuye a definir la identidad del escritor.

$\mathrm{Al}$ inmortalizar al autor con el fin de asegurar su consagración y garantizar su pervivencia en el tiempo, los retratos no se limitan a ser meros umbrales decorativos, sino que interfieren con la experiencia literaria (Dewez/Martens 11) y se convierten en mecanismos que permiten la distinción (Bourdieu 224), definida en este caso por la acumulación del "capital de la visibilidad" que Nathalie Heinich describe como uno de los rasgos constitutivos de la celebridad $(2012,44)$. Para este fin, las fotografías, ilustraciones o esculturas del escritor han mantenido unos códigos que confirman la relevancia del individuo al que identifican, bien a través de su repetido emplazamiento como antesala de los libros o en la prensa o de la insistencia en ciertas poses: la mano apoyada en la cabeza, la inclusión en el encuadre de objetos asociados a la lectura y la escritura como el escritorio, la pluma o los anaqueles llenos de libros (González Treviño 43).

Sin embargo, concebido como un garante de la distinción, el análisis de este tipo de retratos encierra una mayor complejidad cuando quien aparece identificado en él es un sujeto privado históricamente del capital simbólico que dota del prestigio, el mérito y la autoridad que señalan al autor en el régimen de singularidad (Heinich 2018, 27). Tal es el caso de las mujeres que acceden a estas herramientas de promoción tras insertarse progresivamente en la esfera cultural a lo largo del siglo XX y cuya obra ha estado sometida a diversos juicios que históricamente han subrayado su condición extraña o anómala con respecto a la representación dominante del autor (Russ 85; Planté 97-99; Pérez Fontdevila 2019, 34-43). Desde hace varias décadas, uno de los objetivos fundamentales de la teoría literaria feminista ha sido poner de manifiesto hasta qué punto la lógica binaria que organiza el pensamiento patriarcal en los pares naturaleza/cultura, y, en especial, creación/procreación, resulta igualmente determinante para restringir el acceso de las mujeres a la autoría (Gilbert/Gubar 18-19; Cixous 14-15; Stanford Friedman). Ahora, es indispensable valorar cómo se refleja esta aparente incompatibilidad a través de soportes como la fotografía, que son indispensables para la definición del autor en el espacio social. Desde esta perspectiva, solo recientemente se han puesto en relación los estudios de género con los trabajos centrados en el análisis de la figura autorial anteriormente citados (Pérez Fontdevila/Torras Francès 2019, 10-11), lo que permite avanzar en la comprensión de las tensiones entre las escritoras y los distintos medios que determinan su entrada en el espa- 
cio social sin dejar de prestar atención a la subjetividad negada por el ensayo de Barthes.

Por una parte, comprendiendo el retrato del autor como un documento que pretende reflejar la soberanía artística y la excelencia que condicionan la consagración, urge preguntarse en qué medida los procesos de desautorización de las obras escritas por mujeres atraviesan también las fotografías. Por este motivo, junto con la revisión de las ideas que a lo largo de los siglos se han vertido sobre la escritora, ya documentadas para el caso español en trabajos como los de Fernández y Ortega, es necesario evaluar cómo al descubrir el cuerpo de la autora se escenifica una identidad autorial (Meizoz 2015) y de género (Butler 55-56) que, leída desde la normatividad masculina asociada a ambas categorías, determinará la producción de distintos discursos que constituirán una parte fundamental de la "imagen de autora" (Maingueneau).

Por otra parte, la utilización de la fotografía para la promoción de las obras de las escritoras no solo corrobora el camino hacia la profesionalización emprendido por muchas de ellas a través de los medios disponibles a su alcance, sino que, además, pone de manifiesto la existencia de otras formas de autoría que no coinciden con la imagen dominante del escritor configurada en torno a las características arriba mencionadas. En este sentido, es imprescindible valorar hasta qué punto la corporeidad femenina se recupera en el dispositivo fotográfico para definir una nueva identidad autorial que escapa tanto de los moldes de las representaciones canónicas del autor como de las de género. La desarticulación en los nuevos estudios autoriales tanto de la noción de autor como sujeto pleno como de la autonomía del texto o del lenguaje que había propuesto Barthes (Pérez Fontdevila/Torras Francés 2016) permite recuperar estos "casos de autora" (Cróquer Pedrón), que, en general, han sido interpretados con extrañeza en el marco de la normatividad cultural. Si, como considera Jérôme Meizoz, los autores recurren a una larga tradición de gestos y códigos a partir de los que asumen una "postura" que permite reconocerlos como tales (Meizoz 2015, 18-19), será necesario analizar cómo, a través de la iconografía, las escritoras incorporan y transforman a un tiempo dicha historia postural con el fin de superar los límites impuestos a las mujeres en el acceso a la autoría. Así leídos, los retratos constituyen de por sí una ruptura con la corporalidad tradicionalmente asociada al escritor, a la vez que revelan una pugna contra la fisicidad a la que se ha reducido a las mujeres con el fin de establecer una nueva relación entre escritura, cuerpo y autoridad. 
Con este objetivo, me detendré en la iconografía de Ángela Figuera Aymerich (Bilbao 1902-Madrid 1984), entendiéndola como una continuación de su obra literaria, estrechamente vinculada con la poesía social de la posguerra española, y como un documento clave para estudiar las representaciones de la autora en el campo cultural español de los años cincuenta. Los tres ejemplos que se estudiarán constituyen una muestra muy precisa de la imagen mediática de la poeta y ponen de manifiesto que el significado de cada retrato no es unívoco, sino que varía según los espacios editoriales en los que se incluya. Como se verá, antologías, libros propios y entrevistas presentan interesantes variaciones dependiendo del resto de elementos que acompañen a la fotografía, sean estos poemas, ilustraciones o los comentarios de críticos o antólogos. ${ }^{1}$

\section{MATERNIDADES LITERARIAS: DEL CUERPO EN LOS POEMAS AL CUERPO}

DE LA AUTORA

Desde el primero de los libros de Ángela Figuera Aymerich, Mujer de barro (1948), hasta el último, Toco la tierra. Letanías (1962), la maternidad funciona en su obra como un eje central que, a lo largo de los años en los que esta se desarrolla, se irá amoldando a nuevas preocupaciones estilísticas y temáticas (Quance 17). El carácter aglutinador de este tema tiene implicaciones para la construcción de la identidad autorial que deben ser expuestas antes de abordar los retratos de la autora, ya que, si bien su poesía se desplaza desde el intimismo del primero de sus libros, Mujer de barro, hasta la adopción de la poética social que caracterizará su producción posterior al año 1950, la afirmación de la diferencia, a través de la maternidad, será una constante que se manifestará también en el elemento fotográfico.

Ya en Mujer de barro la identificación de imágenes del parto y de la crianza con la escritura supone un intento de legitimar la natural predisposición de las mujeres para la actividad literaria y, en consecuencia, una forma de sub-

1. A pesar del interés de la adopción de esta perspectiva para comprender las relaciones de las escritoras de este periodo con los órganos de reconocimiento, aún no se ha avanzado en el estudio de la imagen mediática de las autoras de posguerra. Poetas como Gloria Fuertes, cuyos atributos físicos llegaron a ser caricaturizados en conocidas imitaciones televisivas (Vila-Belda 18), y narradoras como Carmen Laforet, Ana María Matute o Carmen Martín Gaite, que accedieron al campo cultural español de la mano de premios con tanta repercusión como el Nadal, vieron sus retratos repetidamente reproducidos en los medios de comunicación, faceta que ha sido determinante para el recibimiento de sus obras. 
versión tanto de los roles tradicionales de género que el Régimen tenía como uno de los principales pilares en la educación de las mujeres (Nash 1995, 197), como de la representación tradicional del escritor. Este posicionamiento quedaba claramente condensado en los siguientes versos de aquel primer conjunto, con los que validaba la escritura de las mujeres al conjugar creación y procreación (Stanford Friedman 49) y romper así el binomio mente/cuerpo que está en la base de la cultura patriarcal: "Pero mis versos nacen redondos como frutos, / envueltos en la pulpa caliente de mi carne" (Figuera Aymerich 1986, 60). Aunque en estos textos la voz poética se sitúe a sí misma entre las paredes del hogar, esa "insistencia del yo poético en identificarse como escritora" (Ugalde 77) supone una característica de vital importancia para comprender la voluntad de participar en el campo literario sin dejar de escribir, dando cuenta de aquellas preocupaciones que han sido tradicionalmente desplazadas del universo del autor por su cercanía con la naturaleza (Pérez Fontdevila 2019, 27-30). No ha de perderse de vista que su obra se desarrolla en un contexto de arraigado rechazo a la dedicación de las mujeres aquellas tareas vinculadas al intelecto, ${ }^{2}$ hostilidad hacia la producción literaria femenina que llevó a que gran parte de las escritoras de posguerra situaran las tareas de cuidado en el centro de su universo creativo, o que expresaran públicamente su voluntad de priorizarlas sobre su trayectoria literaria. ${ }^{3}$

Con todo, es necesario insistir en que, si bien la recurrencia a la maternidad como tema localiza a las escritoras en el marco de lo que es propio de su género y, por tanto, puede contribuir a que sean aceptadas dentro de los valores de la feminidad de su época, este es, a su vez, un primer paso para la subversión del orden social. En el caso de Ángela Figuera Aymerich, este nexo entre maternidad y escritura, que queda blindado desde su obra temprana, supone la recuperación de la autoridad para escribir "desde su condición de

2. Este rechazo a la actividad intelectual de las mujeres está estrechamente relacionado con el pensamiento pronatalista del régimen de Franco, que fue determinante para que, como ha estudiado Mary Nash, las mujeres quedaran "politizadas a través de la noción de un destino femenino común determinado por su capacidad reproductora" (Nash 1996, 280).

3. Como bien ha anotado Blanca Ripoll Sintes al estudiar la relación de Carmen Laforet con la prensa, esta voluntad de priorizar las tareas domésticas sobre la escritura, que se revelaría como una actividad secundaria o una afición, se aprecia en numerosas intervenciones públicas de las autoras de este periodo. Así, al ser preguntada por el dinero obtenido con el Premio Menorca, Laforet respondía de este modo: "No sé... mi casa, mis hijos, mi marido, mis amigos..." (Ripoll Sintes 185). La referencia a la maternidad, como tema o como parte de la presencia mediática de las escritoras, contribuye en parte a minimizar la amenaza que escribir supone para los valores vigentes en torno a la feminidad durante la etapa franquista. 
mujer" (Payeras 20) y, así, en cierto modo, su propuesta resulta similar a la "écriture femenine" de Hélène Cixous, ya que, como propone esta última, la poeta vasca emplea aquellas imágenes que han sido recurrentes en la tradición patriarcal para referirse al cuerpo femenino con el fin de promover una propuesta alternativa (56-58). Este es punto de partida para un feminismo desde la diferencia, que repercute en la construcción tanto de la identidad femenina como de la identidad literaria, porque si, como explica Cixous (56), el cuerpo ha servido para apartar a las mujeres de toda actividad intelectual, será este justamente el campo de batalla de la definición de una nueva forma de autoría desde el compromiso y la diferencia. A partir del año 1950, con la publicación de Vencida por el ángel, la obra de Ángela Figuera Aymerich comienza a acercarse a la poesía social de posguerra mediante la denuncia explícita en sus poemas de las condiciones de vida bajo el franquismo, pero la toma de conciencia contra la injusticia social y la defensa de una poesía contra la precariedad humana estará atravesada, una vez más, por el tema de la maternidad (Quance 18). La maternidad estará presente en sus metáforas para definir su rechazo al conflicto armado (Arkinstall) y en la concepción de la escritura que va desgranando en sus poemas y poéticas desde el primero de sus libros. Al hacer compatible creación y procreación, maternidad y escritura, la poeta transita hacia una "postura" (Meizoz 2015), entendida aquí como "la presentación de sí que hace un escritor tanto en la gestión del discurso como en sus conductas públicas" (Meizoz 2014, 86), que se verá reflejada en todas las piezas que produce y que en torno a ella se van gestando y que ponen de manifiesto hasta qué punto lo femenino resulta excepcional en el contexto de las corrientes estéticas dominantes en cada periodo.

En este contexto, con el fin de analizar hasta qué punto la iconografía desempeña un papel relevante en la construcción de la "imagen de autora" de Ángela Figuera Aymerich, resulta pertinente situarse en un momento posterior a la publicación de Belleza cruel (1958), ya que, tras el éxito de este libro, la obra de la poeta adquiere un mayor grado de visibilidad que se materializa

4. Hélène Cixous comprende la "écriture femenine" como forma de resistencia a los discursos binarios que determinan "el conjunto de sistemas simbólicos -arte, religión, familia, lenguaje-" (14) y que, en consecuencia, han estado en la base de la exclusión de las mujeres del espacio creativo. Se trata de una escritura que disuelve los polos "identidad/diferencia" que han servido para identificar al hombre con el ser y que han jerarquizado "la diferencia sexual valorizando uno de los elementos de la relación" (37). No se trata, pues, de ligar la escritura al sexo biológico, sino de desplazar los "significantes y significados" (Pérez Fontdevila 2019, 51) que han servido para privar a lo femenino de la excepcionalidad que es requisito de la autoría. 
en la inclusión de sus textos en antologías poéticas (Castellet; Luis; Mantero), en la proliferación de notas de prensa (Cano; Alfaro; Jiménez Martos) y entrevistas (Núñez) y, en consecuencia, en un aumento considerable en la reproducción de sus retratos. Entre ellas, destaca una fotografía (figura 1) que, además de reproducir las características codificadas del retrato del autor a las que me he referido, refleja con efectividad las tensiones entre el género y la asunción de una "postura" vinculada con la poesía social, tendencia dominan-

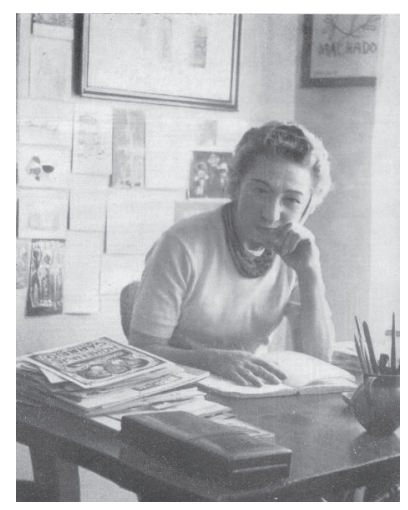

Figura 1. Herederos de Ángela Figuera Aymerich. te en el panorama poético de la posguerra española. Se trata de la incluida en la primera edición de la antología Poesía social de Leopoldo de Luis, una de las selecciones que más importancia ha tenido para la canonización en las historias de la literatura posteriores de nombres vinculados a la poesía del compromiso. En ella se muestra a la poeta tras su mesa de trabajo, en la pose por excelencia de las iconografías del escritor: mientras que la mano izquierda está apoyada en la cabeza, la derecha reposa sobre el papel, conectando el "órgano por excelencia de la escritura" (Dewez/Martens 16) con su soporte. Este encuadre, que ha pervivido a lo largo de la historia, parece remitir a una conexión de la escritura con la mente más que con el cuerpo, de modo que la poeta se acogería al régimen de singularidad patriarcal que ha caracterizado este tipo de fotografías (González Treviño 61).

Pero el retrato introduce además otros elementos que contribuyen a dotar de sentido a la iconografía desde el estudio de la "postura" asumida por la poeta. La habitación enmarca estos atributos corporales e incluye, entre otros, un objeto que destaca sobre los demás: en la pared derecha se aprecia el cartel con la ilustración de Pablo Picasso para el homenaje de Collioure a Antonio Machado del año 1959. Este encuentro supone el acto fundacional del llamado grupo de Barcelona y de la poética social-realista y el afianzamiento de Antonio Machado como modelo ideológico y estético de quienes se identifican con esta tendencia (Iravedra; Riera). La presencia en el retrato del cartel del homenaje funciona como una herramienta de legitimación en el contexto de la poesía social, ya que, al situar al referente masculino de prestigio en el que será su carta de presentación en la antología de Leopoldo de Luis, Ángela Figuera Aymerich se reivindica como deudora del magisterio machadiano 
más allá de las fronteras del texto, influencia que revela una voluntad de insertarse en el campo literario de su tiempo a partir de ciertos rasgos posturales que implican también a la iconografía. De esta manera, la elección de este espacio para la realización del retrato tiene unas fuertes implicaciones en la identidad asumida, cuyo significado depende muy estrechamente de la escena literaria en la que como poeta tiene la voluntad de participar. Desde la pose elegida hasta los objetos que rodean a la autora, se pone de manifiesto cómo su inclusión en volúmenes destinados a la consagración lleva aparejada una serie de estrategias de autorrepresentación que le permiten definirse como autora por encima de las limitaciones que el campo literario impone a los sujetos marcados por el género. Como ha sido ampliamente señalado (Planté 105-14), ha habido históricamente una tendencia a la masculinización de aquellas escritoras que consiguen hacerse un hueco en los órganos de reconocimiento, ${ }^{5}$ lo que ha supuesto que, en muchas ocasiones, exista una voluntad explícita por parte de las creadoras de enfatizar aquellos atributos que las alejan de la feminidad con el fin de entrar a formar parte de los grupos de prestigio. En este sentido, Christine Planté se refiere a la "ambivalencia" que "resurge en los discursos de las mismas mujeres escritoras, a quienes les gusta ser admiradas como excepcionales y sobre todo escapar así de las maldiciones que pesan sobre su sexo" (Planté 98). Esta ambivalencia aparece con claridad en la fotografía comentada, ya que si, por un lado, el retrato supone adoptar ciertos códigos que funcionan como herramientas de "distinción" y neutralizan los rasgos femeninos del cuerpo que escribe con el objetivo de vencer la histórica exclusión de las mujeres de la creación cultural, por otro, este modo de presentarse contrasta con el peso que la maternidad tiene en los poemas.

5. Desde el siglo XIX, con el progresivo acceso de las mujeres al campo cultural, la historia de la literatura española es fuente de numerosos ejemplos de esta tendencia. Al conocidísimo "es mucho hombre esta mujer", atribuido a varios comentaristas de la obra de Gertrudis Gómez de Avellaneda (González-Allende 38), es necesario añadir la reseña que Leopoldo Alas ("Clarín”) publicó de Insolación (1889) de Emilia Pardo Bazán como una de las muestras más destacadas de este prejuicio. En ella, Alas recurría a la última novela de la escritora gallega para rechazar el travestismo sexual asumido por muchas autoras y defender la carencia de talento en una mujer en relación con sus atributos femeninos: "que nosotros, aun en presencia del más robusto ingenio, ante la más acreditada fama de un talento de hombre superior... en una mujer, suspiremos por algo que falta" (5455). Ante estas palabras, no es descabellado pensar que, como ha observado María del Carmen Alfonso García, los discursos de hombres tan reconocidos como el autor de La Regenta llevaran a que Emilia Pardo Bazán adoptara "con plena consciencia, un modo masculinizante con el que se propone superar lo que juzga caducos presupuestos respecto de la imagen que cabe forjarse no sólo de una mujer, sino también de una novelista. Acaso no hubiese otra alternativa si lo que se quiere es trascender el arquetipo dependiente del ángel del hogar, etéreo y pasivo" (Alfonso García 127). 
Si se tiene en cuenta que las antologías poéticas constituyen uno de los soportes que mejor revela el carácter excepcional de las escritoras en la tradición literaria (Russ 76-79), se comprenderá la importancia que el retrato adquiere como llave de paso a los poemas seleccionados, ya que, al representar a un sujeto femenino fomentará una determinada lectura de los textos a los que la iconografía tiene la función de identificar. Así, es necesario establecer una relación entre palabra e imagen para estudiar cómo se elabora una "postura" autorial en ambos planos. En este caso, si el retrato revela la necesidad de acogerse a los rasgos codificados por la tradición a través de la pose y de los elementos que contribuyen a legitimar al sujeto que lo protagoniza, la poética que lo sucede evidencia en qué medida la obra de Ángela Figuera Aymerich bebe directamente de la retórica de la poesía social de posguerra sin renunciar a la asunción de una voz que se aleja de la norma. En ella, la voluntad de utilizar el texto como herramienta de cambio social (Figuera Aymerich 1965, 66), compartida con gran parte de poetas de la antología, convive con la resolución de hacerlo desde el "amor de mujer y de madre" (65). Introduce así en las coordenadas estéticas dominantes de la posguerra una nueva forma de comprometerse a través de la literatura y de autorrepresentarse como escritora. Sin embargo, esta presentación, que, sin renunciar a la poesía social, se expresa a través de una identidad de género que parece contradecir la que ha identificado al autor, ha de ser contrastada con cómo es recibida por parte de la prensa, sector fundamental en la consolidación de ciertos nombres en el canon literario.

Desde esta perspectiva, otra de las fotografías (figura 2) de la escritora que

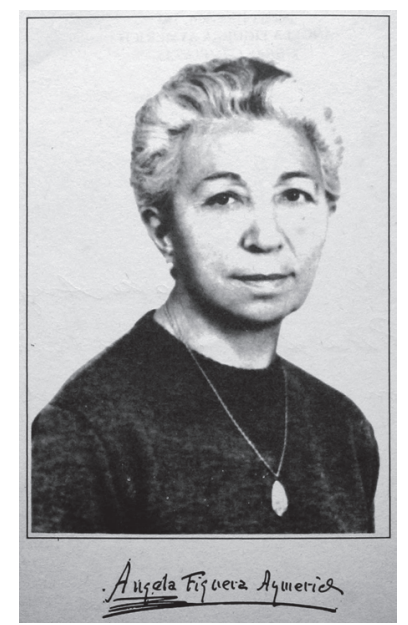

Figura 2. Ediciones Hiperión. también encierra un gran interés por el vínculo que establece con el discurso de un agente externo es la que acompaña la entrevista realizada por Antonio Núñez con motivo de la publicación de su Antología total en el año 1973 (Figuera Aymerich 1973). Este resulta un buen ejemplo a la hora de abordar hasta qué punto el aspecto físico de las escritoras interfiere no solo con sus propias declaraciones en torno a la creación poética, como ocurría con el caso anterior, sino también con los juicios de otros que se provocan con su acceso al campo literario. En este caso, la fotografía, tomada de hombros hacia 
arriba, muestra a la poeta a una edad avanzada, sin nada que desvíe la atención de su rostro. Su interés reside en la interacción con el texto de la entrevista y en el modo como simultáneamente conforman la "imagen de autora", comprendida en la confluencia de sus textos y gestos, "y las palabras de todos los que, de modos diversos y en función de sus intereses, contribuyen a modelarla" (Maingueneau 21). Al describir a la poeta como "entrañable escritora", "menuda, acogedora" (Núñez 327), el periodista contribuye a ofrecer una lectura determinada tanto de los poemas recogidos en la antología que se pretende publicitar, como de la iconografía que acompaña a estas palabras. Leído juntamente con el texto de Núñez, que se refiere a rasgos que aproximan a la autora a lo material, lo que destaca en la reproducción de este retrato es que, lejos de funcionar como un mecanismo de distinción, se rompe la identificación que el cuerpo del retrato establece con la obra y fomenta una lectura en los términos de repetición y materialidad que han caracterizado las respuestas a la presencia de las escritoras en el campo cultural y que han definido a la mujer en el espacio público.

Muy distintos son los significados que esta misma fotografía parece adquirir posteriormente, con su reproducción al frente de las obras completas de la escritora, publicadas por la editorial Hiperión dos años después de su muerte (Figuera Aymerich 1986). Si en la entrevista de 1974 los juicios de Núñez parecían impedir cualquier vínculo entre el cuerpo del retrato, sexuado en femenino, y la obra y, por tanto, entre género y autoría, la reproducción en este volumen estará ligada, por el contrario, al mérito que se asocia a la reunión del conjunto de los textos tras el fallecimiento. En esta nueva utilización del retrato se incluye un elemento que resulta capital para dotar de un nuevo sentido a esta iconografía: la firma que se añade en el pie de la foto y que ha constituido uno de los objetos de mayor interés para los estudios en torno al autor. Entre las aportaciones fundamentales, es necesario rescatar el concepto de Jacques Derrida de la firma como "un intento de recuperar lo propio de lo que se ha visto desapropiar rápidamente en el nombre" (Derrida 164), ya que, si con el filósofo francés se tiene en cuenta que la firma supone un retorno del yo, con el apoyo de la rúbrica, el retrato recobraría aquí su faceta como mecanismo de distinción y permitiría la acumulación del capital de la visibilidad por parte de un sujeto que no cumple con las características que tradicionalmente son requeridas para ocupar una posición de reconocimiento en el campo literario. Sin embargo, ha sido Peggy Kamuf, una de las más autorizadas lectoras de Derrida, quien mejor ha observado las dificultades de reducir la obra y, por extensión, a su autora, al nombre de la signataria. Atribuir una identidad femenina a 
un texto mediante la distinción biológica entre lo masculino y lo femenino supone ceder al determinismo que ha condicionado la interpretación de los escritos de las mujeres a lo largo de los siglos (Kamuf 206-07). Con todo, "la lectura de un texto como si hubiera sido escrito por una mujer exigirá leerlo como si no tuviera un padre (determinado), como si, en otras palabras, fuera ilegítimo, reconocido por su madre, quien solo puede darle un nombre prestado" (226). De este modo, acompañado de la firma, el retrato permite la identificación con la obra, pero la presencia de un cuerpo marcado por el género entorpece la división entre la firmante y la autora, que será retomada por los medios.

En este sentido, es necesario tener en cuenta una última fotografía (figura 3) que resulta esclarecedora cuando se analiza la identificación entre el retrato, la firma y las obras. Es aquella en la que Ángela Figuera Aymerich aparece con su hijo todavía bebé, fechada en el año 1937, y que se reproduce en el número monográfico que la revista Zurgai dedica a la poeta en 1987, junto al artículo "Erotismo, maternidad y paisaje en la primera poesía de Ángela Figuera" (Zabala Aguirre). Como se revela en la página de créditos de la revista, no fue el autor del ensayo quien escogió este retrato para acompañar el texto, sino que del apartado iconográfico se ocuparon José María Muñoz, Julián Vallejo y Poti Eguidazu. No por ello se le debe restar importancia al paralelismo que se fomenta entre la imagen y el discurso crítico, ya que, además,

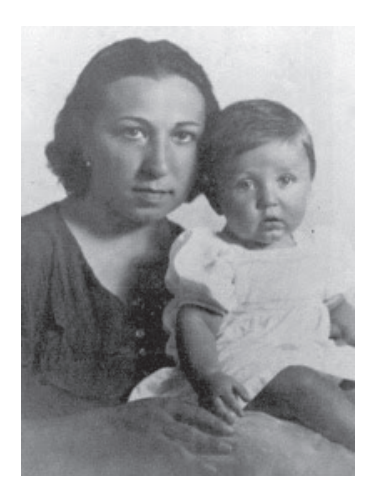

Figura 3. Herederos de Ángela Figuera Aymerich. permite subrayar el carácter colectivo de la autoría en el régimen mediático. Por otro lado, por tratarse de un documento del archivo personal, no estaría de antemano destinado a la promoción de sus obras y, por ello, resulta muy diferente a los comentados anteriormente. Es justamente su naturaleza privada lo que permite establecer nuevos lazos entre el retrato y la elaboración de la "imagen de autora" tras la muerte de la escritora, que han de ser puestos en relación con la fotografía de las Obras completas previamente analizada. ${ }^{6}$

6. Es necesario tener en cuenta que, si bien Dominique Maingueneau no le resta importancia al proceso de construcción de la "imagen de autor" a través de las interacciones entre los "gestos y palabras" del escritor y las del resto de la comunidad a lo largo de la vida del autor, el investigador destaca que, en numerosas ocasiones, "la imagen de autor se elabora sobre todo a posteriori, gracias a terceros, cuando el escritor está muerto" (Maingueneau 21). 
En el artículo de José Ramón Zabala Aguirre en el que se reproduce la fotografía, se revisa la poesía practicada al comienzo de la trayectoria de Ángela Figuera Aymerich con el fin de subrayar otras facetas de su obra que se alejan de la vertiente social a la que esta se conecta a partir de los años cincuenta. Con todo, esta reivindicación de Mujer de barro (1948) y Soria pura (1949) trae aparejados ciertos juicios sobre la escritura femenina que están directamente relacionados con la reproducción de un retrato privado en la revista:

Se nos muestra Ángela en todo momento, profundamente marcada por la maternidad, por la labor de educar al hijo tan deseado, por el recuerdo de aquel otro muerto apenas hubo nacido. Encontramos en estos poemas la misma ternura que la caracterizará cuando en sus últimos años, abuela ya, crea cuentos y poesías para sus nietos. (Zabala Aguirre 22)

En este fragmento se exponen dos prejuicios relacionados con la existencia de una autoría que escapa de las representaciones normativas y que parecen apoyarse en la presencia de la fotografía personal en la página del artículo. El primero de ellos responde a la utilización del nombre de pila, contrapunto de la firma reproducida en las cubiertas de los libros y como pie de foto en el retrato estudiado anteriormente. Si la firma garantizaba en el contexto de las Obras completas la pervivencia del nombre a pesar de la desaparición del cuerpo, el nombre de pila parece realizar el camino inverso para incidir en la repetición y la carencia de excepcionalidad, rasgos opuestos a los que han caracterizado al autor en el tejido cultural. Por otro, la propia biografía de la poeta, reflejada en la alusión a la pérdida del hijo y en la conexión de su literatura infantil con su condición de abuela, servirá para ligar los textos al terreno doméstico. La interpretación de la literatura escrita por mujeres desde lo confesional ha sido uno de los tópicos que han operado de forma sistemática en la minusvaloración de la literatura de autoría femenina (Russ 29-31), ya que supone subrayar la imposibilidad de las mujeres de escapar de los moldes de la reproducción para crear una obra original. Se trata de subrayar la espontaneidad y la naturalidad frente a la deliberación que subyacería a aquellos textos verdaderamente universales (Pérez Fontdevila 2019, 38-39). Así, si bien el ensayo acepta la escritura de las mujeres por la conexión con la maternidad que también Ángela Figuera Aymerich había defendido en sus versos, la limita, desde el texto y la iconografía, al ámbito de lo privado. Desde esta perspectiva, el retrato del archivo personal de la poeta difiere de las dos fotografías comentadas anteriormente no solo por no corresponder con la faceta profesio- 
nal, sino también por identificarse con poemas anunciados bajo el nombre de pila (utilizado por el crítico) y no por la firma "Ángela Figuera Aymerich”, que tanto en la antología Poesía social como en las Obras completas contribuía a hacer de los retratos herramientas de distinción necesarias para el reconocimiento como autora.

Sin embargo, para comprender la importancia que la recuperación de este retrato tiene tras la muerte de Ángela Figuera Aymerich, resulta imprescindible analizarlo en relación con la ilustración de cubierta de la primera edición de Mujer de barro (1948) (Figuera Aymerich 1948), uno de los volúmenes que merece la atención del artículo de José Ramón Zabala Aguirre, ya que el dibujo, sin identificarse directamente con los atributos físicos de la escritora, establecerá una estrecha correspondencia con la instantánea y con la "postura" asumida en textos como la poética de Poesía social (Figuera Aymerich 1965) comentada previamente. El sencillo bosquejo de una mujer sosteniendo en brazos a un bebé servirá para sugerir que la maternidad es el tema que articula el primer libro de Ángela Figuera Aymerich, pero la importancia de esta imagen se acentuará al ser reproducida de nuevo frente a las mencionadas Obras completas de 1986 (figura 4), donde indicará el cierre de la trayectoria literaria de la poeta. Al colocarse en ambos libros, junto con el nombre de la autora, esta ilustración enlaza la maternidad biológica con la maternidad literaria, equivalencia que será la base de una escritura desde la diferencia en los poemas. La especial significación reside en que,

Ángela Figuera Aymerich
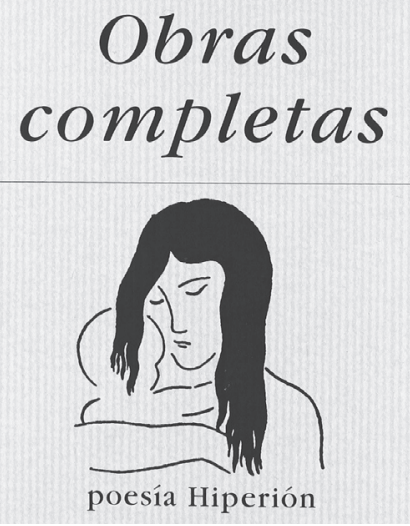

Figura 4. Ediciones Hiperión. ubicada próxima a la firma en los dos volúmenes, la ilustración dota de unidad a textos diversos (Pérez Fontdevila 2017, 30) y contribuye a elaborar una serie de ideas en torno a una autoría que se asume en femenino. Así, la maternidad, expresada en forma de imágenes y palabras, no solo se convierte en el tema principal de su literatura, tal como se ha señalado anteriormente (Quance 17), sino en una carta de presentación desde la que se asume que el reconocimiento en el campo cultural es indisociable de su identidad de género. Desde la iconografía se propone también una "escritura femenina" como la defendi- 
da por Hélène Cixous, ya que el trabajo de cuidado se legitima como un espacio desde el que proclamar la singularidad que es requisito para la definición de la figura autorial.

Por lo contrario, la fotografía incluida en el monográfico de Zurgai, claramente emparentada con esta ilustración, ponía de manifiesto la difícil compatibilidad entre el tratamiento de temas que han servido para caracterizar a la identidad femenina y su utilización como parte del universo de la autora. Las iconografías adquieren así un significado que también está supeditado a un conjunto de procesos colectivos en los que intervienen distintos agentes y sin los que es imposible conocer el lugar de las escritoras tanto en el periodo en el que desarrollaron su obra como después de su muerte. En este sentido, los retratos estudiados en este trabajo perfilan una "imagen de autora" (Maingueneau) de Ángela Figuera Aymerich que no es unívoca, sino que depende del lugar en el que aparecen, los comentarios producidos en torno a ellos por antólogos y críticos, y las palabras de la propia poeta. Al mostrar corporalidades que no coinciden con las representaciones canónicas del autor, cada uno de los ejemplos mostrados es motor de distintas representaciones: mientras que su inclusión en una antología generalista y al frente de las obras completas revelaba una voluntad de legitimarse como autora en un contexto de canonización, su reproducción en la prensa fomenta comentarios de desautorización que frustrarán la conciliación entre autoría y género.

En definitiva, el estudio de estas tres fotografías y de los elementos de los que van acompañadas demuestra que su significado está supeditado al acervo de discursos que responden al progresivo acceso de las mujeres a la esfera cultural y abre un profundo debate sobre la importancia de los retratos en la lucha de las escritoras por la consagración, lo que los convierte en un documento muy relevante a la hora de analizar nociones como las de "postura" (Meizoz 2015) o "imagen de autor" (Maingueneau). La presencia de un cuerpo ajeno a la norma en los espacios editoriales designados para la reproducción del aspecto físico del autor resulta un paso fundamental para la autorización de la escritura de mujeres, si bien, debido a la incompatibilidad que el "régimen de singularidad" (Heinich 2018) patriarcal introduce entre género y autoría, esta reviste una complejidad que ha de ser analizada en relación con el marco abierto por los recientes estudios autoriales. Solo recomponiendo cada una de estas piezas será posible alcanzar una comprensión cabal de los retos a los que las escritoras españolas contemporáneas se han enfrentado con el fin de ser recibidas como autoras. 


\section{OBRAS CITADAS}

Alas, Leopoldo (“Clarín”). "Emilia Pardo Bazán y sus últimas obras”. Folletos literarios. VII. Museum (mi revista) 1 (1890): 51-88.

Alfaro, Maria. “Belleza cruel, de Ángela Figuera”. Ínsula 146 (1959): 10.

Alfonso García, María del Carmen. "De Insolación (1889), de Emilia Pardo Bazán, a La insolación (1963), de Carmen Laforet: ¿nibil novum sub sole?”. La literatura de Emilia Pardo Bazán. Eds. José Manuel González Herrán, Cristina Patiño Eirín y Ermitas Penas Varela. A Coruña: Real Academia Galega, 2009. 125-35.

Amossy, Ruth. "La doble naturaleza de la imagen de autor". La invención del autor: nuevas aproximaciones al estudio sociológico y discursivo sobre la figura autorial. Ed. Juan Zapata. Medellín: Universidad de Antioquía, 2014. 67-84.

Arkinstall, Christine. "Rhetorics of Maternity and War in Ángela Figuera's Poetic Work". Revista Canadiense de Estudios Hispánicos 21.3 (1997): 457-78.

Barthes, Roland. El susurro del lenguaje: más allá de la palabra y la escritura. Barcelona: Paidós, 1987.

Bourdieu, Pierre. La distinción: criterio y bases sociales del gusto. 3. ${ }^{a}$ ed. Barcelona: Taurus, 2016.

Butler, Judith. El género en disputa: el feminismo y la subversión de la identidad. Barcelona: Paidós, 2007.

Cano, José Luis. "Los libros del mes: tres libros de poesía”. Ínsula 156 (1958): 6-7.

Castellet, José María. Veinte años de poesía española: antología 1939-1959. Barcelona: Seix Barral, 1960.

Cixous, Hélène. La risa de la medusa: ensayos sobre la escritura. Barcelona: Anthropos, 1995.

Cróquer Pedrón, Eleonora. "Curriculum Vitae: notas para una definición del «caso de autor»". Los papeles del autor/a: marcos teóricos sobre la autoría literaria. Eds. Aina Pérez Fontdevila y Meri Torras Francés. Madrid: Arco Libros, 2016. 107-28.

Derrida, Jacques. "La firma”. Facques Derrida. Eds. Geoffrey Bennington y Jacques Derrida. Madrid: Cátedra, 1994. 162-79.

Dewez, Nausicaa, y David Martens. "Iconographies de l'écrivain: Du corps de l'auteur au corpus de l'œuvre”. Interférences littéraires 2 (2009): 11-23.

Diaz, José-Luis. L'Ecrivain imaginaire: Scénographies auctoriales à l'époque romantique. Paris: Honoré Champion, 2007. 
Fernández, Pura, y Marie-Linda Ortega, eds. La mujer de letras o letraherida: discursos y representaciones sobre la mujer escritora en el siglo XIX. Madrid: CSIC, 2008.

Ferrari, Federico, y Jean-Luc Nancy. Iconographie de l'auteur. Paris: Galilée, 2005. Figuera Aymerich, Ángela. Mujer de barro. Madrid: Saeta, 1948.

Figuera Aymerich, Ángela. "Poética". Poesía social: antología. Ed. Leopoldo de Luis. Madrid: Alfaguara, 1965. 65-67.

Figuera Aymerich, Ángela. Antología total. Madrid: CVs, 1973.

Figuera Aymerich, Ángela. Obras completas. Madrid: Hiperión, 1986.

Foucault, Michel. “¿Qué es un autor?”. La invención del autor: nuevas aproximaciones al estudio sociológico y discursivo de la figura autorial. Ed. Juan Zapata. Medellín: Universidad de Antioquia, 2014. 33-48.

Gilbert, Sandra M., y Susan Gubar. La loca del desván: la escritora y la imaginación literaria del siglo XIX. Madrid: Cátedra, 1998.

González-Allende, Iker. "Entre la modestia y el orgullo: las coordenadas metapoéticas de Carolina Coronado". Decimonónica 1.1 (2004): 33-51.

González Treviño, Ana Elena. "Caras vemos...: el retrato del autor en el libro impreso, un muestrario histórico". Estudios 21.42 (2013): 43-63.

Heinich, Nathalie. De la Visibilitée: Excellence et singularité en régime médiatique. Paris: Gallimard, 2012.

Heinich, Nathalie. L'Elite artiste: Excellence et singularité en régime démocratique. Paris: Folio, 2018.

Iravedra, Araceli. "Cuando de aquello también hacía veinte años". Ínsula 745746 (2009): 2-6.

Jiménez Martos, Luis. “Ocho poetisas”. Ágora 29-30 (1959): 51-54.

Kamuf, Peggy. "Escribir como mujer". Otramente: lectura y escritura feministas. Ed. Marina Fe. México: FCE, 1999. 204-27.

Luis, Leopoldo de. Poesía social: antología. Madrid: Alfaguara, 1965.

Maingueneau, Dominique. "Escritor e imagen de autor". Tropelías 24 (2015): $17-30$.

Mantero, Manuel. Poesía española contemporánea (1939-1965). Barcelona: Plaza \& Janés, 1966.

Martens, David, y Anne Reverseau. "La Littérature dévisagée: Figurations iconographiques de l'écrivain au xxe siècle". Image \& Narrative 13.4 (2012): 1-10.

Meizoz, Jérôme. "«Aquello que le hacemos decir al silencio»: postura, ethos, imagen de autor". La invención del autor: nuevas aproximaciones al estudio 
sociológico y discursivo de la figura autorial. Ed. Juan Zapata. Medellín: Universidad de Antioquia, 2014. 85-96.

Meizoz, Jérôme. Posturas literarias: puestas en escena modernas del autor. Bogotá: Universidad de los Andes, 2015.

Nash, Mary. "Identidades, representación cultural y discurso de género en la España Contemporánea". Cultura y culturas en la bistoria. Eds. Pedro Chalmeta, Fernando Checa Cremades y Manuel González Portilla. Salamanca: Universidad de Salamanca, 1995. 191-203.

Nash, Mary. "Pronatalismo y maternidad en la España franquista". Maternidad y políticas de género: la mujer en los estados de bienestar europeos, 18801950. Eds. Gisela Bock y Pat Thane. Madrid: Cátedra, 1996. 279-307.

Núñez, Antonio. "Encuentro con Ángela Figuera". Ínsula 327 (1974): 4.

Payeras, María. El linaje de Eva: tres escritoras españolas de postguerra: Ángela Figuera, Celia Viñas y Gloria Fuertes. Madrid: Sial, 2003.

Pérez Fontdevila, Aina. "Velar al autor: una reflexión en torno a la autoría literaria y el retrato fotográfico". FronteiraZ 7 (2011): 164-71.

Pérez Fontdevila, Aina. Un común singular: lecturas teóricas de la autoría literaria. 2017. Universidad Autónoma de Barcelona, tesis doctoral. <http://hdl.handle.net/10803/402398>.

Pérez Fontdevila, Aina. "Qué es una autora o qué no es un autor". ¿Qué es una autora?: encrucijadas entre género y autoría. Eds. Aina Pérez Fontdevila y Meri Torras Francès. Barcelona: Icaria, 2019. 25-59.

Pérez Fontdevila, Aina, y Meri Torras Francés. "La autoría a debate: textualizaciones del cuerpo-corpus (una introducción teórica)". Tropelías 24 (2015): 1-16.

Pérez Fontdevila, Aina, y Meri Torras Francés, eds. Los papeles del autor/a: marcos teóricos sobre la autoría literaria. Madrid: Arco Libros, 2016.

Pérez Fontdevila, Aina, y Meri Torras Francés. "El género de la autoría”. ¿Qué es una autora?: encrucijadas entre género y autoría. Eds. Aina Pérez Fontdevila y Meri Torras Francès. Barcelona: Icaria, 2019. 7-23.

Planté, Christine. "La excepción y lo ordinario". ¿Qué es una autora?: encrucijadas entre género y autoría. Eds. Aina Pérez Fontdevila y Meri Torras Francès. Barcelona: Icaria, 2019. 97-142.

Quance, Roberta. "En la casa paterna”. Ángela Figuera Aymerich. Obras completas. Madrid: Hiperión, 1986. 15-25.

Riera, Carme. La escuela de Barcelona. Barcelona: Anagrama, 1988.

Ripoll Sintes, Blanca. "Carmen Laforet y el Premio Menorca: geografía, novela y premios literarios". Castilla: estudios de literatura 7 (2016): 169-92. 
Russ, Joanna. How to Suppress Women's Writing. 8. ${ }^{a}$ ed. Austin: Texas UP, 2005. Stanford Friedman, Susan. "Creativity and the Childbirth Metaphor: Gender Difference in Literary Discourse". Feminist Studies 13.1 (1987): 49-82.

Ugalde, Sharon Keefe. "Transgredir límites: «Versos que salieron a correr mundo»". Zurgai (diciembre 2009): 76-80.

Vila-Belda, Reyes. Gloria Fuertes: poesía contra el silencio. Literatura, censura y mercado editorial (1954-1962). Madrid: Iberoamericana/Frankfurt am Main: Vervuert, 2017.

Zabala Aguirre, José Ramón. "Erotismo, maternidad y paisaje en la primera poesía de Ángela Figuera”. Zurgai (diciembre 1987): 20-23. 